\title{
Antimicrobial Efficacy of Two Shrubs (Punica granatum and Camellia sinensis) and an Herb (Mentha piperita) on Two Human Pathogens, Streptococcus mutans and Streptococcus sanguinis
}

\section{Fatemeh Lavaee', Farzan Modaresi ${ }^{2,3,4 *}$, Kioumars Faez ${ }^{5}$, Negin Esnaashari ${ }^{5}$}

'Department of Oral \& Maxillofacial Disease, School of Dentistry, Shiraz University of Medical Sciences, Shiraz, Iran.

${ }^{2}$ Central laboratory Research, Jahrom University of Medical Sciences, Jahrom, Iran

${ }^{3}$ Department of Microbiology, School of Medicine, Jahrom University of Medical Sciences, Jahrom, Iran

${ }^{4}$ Department of Advanced Medical Sciences and Technology, JahromUniversityof Medical Sciences, Jahrom, Iran.

${ }^{5}$ School of Dentistry, Shiraz University of Medical Sciences, Shiraz, Iran

Study Area:Jahrom, Iran

Coordinates: $28^{\circ} 30^{\prime} \mathrm{oo}^{\prime \prime N}$; $53^{\circ} 33^{\prime} 38: \mathrm{E}$

Key words: Herbal Medicine, Oral disease, Dental Caries, Minimal Inhibitory Concentration

\section{Introduction:}

Dental caries is the most common oral disease which is caused by poor oral hygiene and proceeding cariogenic microorganism accumulation (Holbrook \& Magnúsdóttir, 2012; Ghapanchi et al., 2015; Lavaee et al., 2016; 2018). Oral streptococci in oral cavity are one of the most important cariogenic species in dental plaque (Semyari et al., 2011; Rezazadeh et al., 2016; Ghapanchi et al., 2016). Streptococcus mutans, Streptococcus sanguinis, and Lactobacilli are important acidogenic microorganism in dental caries induction. In the early biofilm Streptococci colonizes primarily (Chhour et al., 2005). Physical and chemical interventions (tooth brushing, dental flossing, and mouth rinses), can decrease supragingival plaque and gingivitis (Palmer et al., 2012). Chlorhexidine is one of the most widely used antimicrobial mouthwashes with some side effects including taste change, teeth and restoration staining (Gunsolley, 2010).

Nowadays many studies focused on herbal substitution instead of the chemical mouthwash to avoid

\section{Abstract}

The antimicrobial activities of Punica Granatum Camelia Sinensis and Mentha Piperita alone and in combination was studied on two human pathogens, Streptococcus mutans ATCC 35668 and Streptococcus sanguinis ATCC 10556 by macro- and micro-broth dilution alone and in combination with two and three extracts. The minimum inhibitory concentrations (MIC) for P.Granutum, C.Sinensis and M.piperita extracts in S.mutans were found as 3.125, 6.25 \& $1.56 \mathrm{mg} / \mathrm{ml}$ respectively, and for S.sanguinis they were 1.56 , $3.125 \& 1.56 \mathrm{mg} / \mathrm{ml}$ respectively. MIC of P.Granutum and C.Sinensis simultaneously in S.mutans were $3.125 \mathrm{mg} / \mathrm{ml}$; S.sanguinis $1.56 \mathrm{mg} / \mathrm{ml}$, P.Granutum and M.Piperita simultaneously in S.mutans were $6.25 \mathrm{mg} / \mathrm{ml}$ and S.sanguinis $3.125 \mathrm{mg} / \mathrm{ml}$; and C.Sinensis and M.Piperita simultaneously in S.mutans were 3.125 and S.sanguinis $1.56 \mathrm{mg} / \mathrm{ml}$, respectively. MIC of P.Granutum, C.sinensis and M.piperita extracts simultaneously in S.mutans were 0.39 and S. sanguinis $0.78 \mathrm{mg} / \mathrm{ml}$, respectively. Conclusively, P.granutum, C.sinensis and M.piperita revealed satisfactorily antibacterial effects on S.mutans and S.sanguinis, using a combination of the three extract makes the synergism antimicrobial effect and had the lowest MIC.

the microbial resistance and other side effects (Vahabi et al., 2011; Palombo, 2011; Hillman et al., 1985 ). A fruit, Pomegranate (Punica granatum) is known historically to cure cancer, cardiovascular diseases, diabetes mellitus, dental diseases, and also bacterial infection. The Asian tree P.granatum Linn is the family of Punicae and it grows well in Iran and northern India, Asian Mediterranean, Europe and Africa. Several parts of pomegranate such as its flowers, trunk skin, fruits, roots and seeds can be used for medical purposes (Jurenka, 2008; Bagri et al., 2009). Recently the antimicrobial properties of P.granatum have been recognised (Vasconcelos et al., 2006; Duman et al., 2009). Various tree parts of P.granatum acts as antimicrobial agent against various microorganisms (Dastjerdi et al., 2014). The antibacterial activity of P.grantum in the oral cavity was well documented by Chinsembu (2016). Camellia sinensis is a shrub of the Thecae family usually, its leaves are used in preparing three different types of tea, Green tea (non-fermented), Oolong tea (semi-fermented) and Black tea (fermented) (Goenka 
et al., 2013; Voravuthikunchai et al., 2004). Green tea, the non-fermented type with the greatest amount of catechin having antimicrobial property, acts as an antioxidant and also able to decreases cholesterol level (Tahir \& Moeen, 2011; Mitscher et al., 1997)

Peppermint (Mentha piperita L.), an aromatic plant of the Labiatae family possess various medicinal properties among which the antibacterial activity result from materials such as menthol, menthone, and their derivatives (Rodrigues et al., 2004). Till date the studies which have been carried out in it are inadequate, lacking proper microbiological approach.

Due to the high prevalence of dental caries and new global efforts for introducing herbal substitute, this study was conducted to evaluate the antimicrobial effects of few potent medicinal plants; Punica granatum, Camelia sinensis, and Mentha Piperita in their lone capacity as well as combined effects against Streptococcus mutans and Streptococcus sanguinis

\section{Materials and methods:}

Preparation of the plant extracts: extracting of plants materials were done by using the following methods. The dried form of these plants was powdered; $50 \mathrm{~g}$ of the plant was soaked in $500 \mathrm{ml} 96 \%$ ethanol at room temperature for 48 hours. The filtrate supernatant was centrifuged (for 10 minutes at $2000 \mathrm{rpm}$ ) and concentrated (on a rotary evaporator at $42^{\circ} \mathrm{C}$ ) in order to eliminate ethanol. The extracts were stored in a refrigerator in sterile bottles (Menezes et al., 2006; Taweechaisupapong et al., 2005).

Activation of microorganisms: standard strains of S.mutans (ATCC 35668, PTCC 1683), S.sanguinis (ATCC 10556, PTCC 1449) in lyophilized form were prepared from the Persian Type Culture Collection center. The brain heart infusion agar (BHIA, Merck, Germany) was used to activate. After incubation at $37^{\circ} \mathrm{C}$, a 24 -hours culture was used for microbial suspension preparation. Using spectrophotometer $(625 \mathrm{~nm})$ the microorganism concentration in the microbial suspension was adjusted to 0.5 McFarland (1.5 $\times 108 \mathrm{CFU} / \mathrm{mL}$ ) (Jorgensen \& Turnidge, 2015).

\section{Minimal Inhibitory Concentration (MIC)}

Broth Macro dilution Method: a standard technique of clinical and laboratory standards institute (CLSI, 2012) was used for MIC determination by the microdilution method. The 0.5 McFarland standard suspensions were diluted from 1 to 150 by serial dilution in BHI broth medium to have 106 $\mathrm{CFU} / \mathrm{mL}$ of bacteria. $1 \mathrm{ml}$ of a diluted microbial suspension was added to the tubes of serially diluted extract. The tubes with only culture medium and extract and tubes with culture medium and microbial suspension were considered as a negative and positive control.

The MIC value of extracts for each bacterial species was measured after 24 hours of incubation at $37^{\circ} \mathrm{C}$. The evaluation was repeated for 3 times against each bacteria.
Broth Microdilution Method: the concentration of each bacteria (S.mutans and S.sanguinis) suspension in Muller Hinton broth was adjusted to10 $7 \mathrm{CFU} / \mathrm{ml}$. Twofold dilution of each herbal extract was prepared from the stock solution. Aliquots $(200 \mu \mathrm{l})$ of each dilution were dispensed in 96-well culture plates after adding 100 microliters of each bacterial suspension to each well and 48 hours incubation at $37^{\circ} \mathrm{C}$, the absorbance was then measured at 595nm. MIC was considered the highest dilution of the extracts at which nogrowth $(\mathrm{OD}=0.05)$ was detected.

Minimum Bactericidal Concentration (MBC): determining the MIC, $20 \mu \mathrm{L}$ of the tube with MIC of each extract and the tube with no bacterial growth was cultured in the plates containing BHIA. After 24 hours of incubation at $37^{\circ} \mathrm{C}$, the plates were evaluated for the growth of microorganisms. MBC was considered as the concentration with no bacterial growth. This test was repeated 3 times for each bacteria.

Statistical analysis: data analysis by using two-way analysis of variance (two way ANOVA) and post hoc tests were performed.

\section{Results:}

While using the macro- and micro-dilution broth method, the extracts of P.granatum, C.sinensis, and M.piperita showed inhibitory effects on the growth and proliferation of S.mutans and S.sanguinis. MIC and MBC values of these extracts for different microorganisms by using macrodilution tests are presented in Tables-1.

Table -1: MIC and MBC of the extracts by macro-dilution test (Mean \pm SE are of triplicates)

\begin{tabular}{llll}
\hline Bacteria & Extracts & $\mathrm{MIC}+\mathrm{SE}$ & $\mathrm{MBC}+\mathrm{SE}$ \\
\hline S. mutans & P. granatum & $3.125+0.01$ & $6.25+0.01$ \\
& C. sinensis & $6.25+0.01$ & $12.5+0.01$ \\
& M.piperita & $1.56+0.01$ & $3.125+0.01$ \\
S. sanguinis & P. granatum & $1.56+0.01$ & $3.125+0.01$ \\
& C. sinensis & $3.125+0.01$ & $6.25+0.01$ \\
& M.piperita & $1.56+0.01$ & $1.56+0.01$ \\
\hline
\end{tabular}

M.piperita and P.granatum had the highest antibacterial effect on S.mutans with MIC and MBC values of 1.56 and $3.125 \mathrm{mg} / \mathrm{ml}$, respectively. MIC and MBC values of this extract for S.mutans and S.sanguinis by using microdilution tests are presented in Table 2.

Table -2: MIC and MBC of the extracts by micro-dilution test (Mean+SE are of triplicates)

\begin{tabular}{llll}
\hline Bacteria & Extracts & MIC + SE & MBC +SE \\
\hline S. mutans & P.granatum & $1.56+0.01$ & $3.125+0.01$ \\
& C. sinensis & $3.125+0.01$ & $6.25+0.01$ \\
& M. piperita & $1.56+0.01$ & $3.125+0.01$ \\
S. sanguinis & P.granatum & $1.56+0.01$ & $3.125+0.01$ \\
& C. sinensis & $3.125+0.01$ & $6.25+0.01$ \\
& M. piperita & $1.56+0.01$ & $1.56+0.01$ \\
\hline
\end{tabular}


RESEARCH ARTICLE

Table-3: MIC and MBC of the combination extract by macrodilution test (Mean \pm SE are of triplicates)

\begin{tabular}{llll}
\hline Bacteria & Extracts & $\mathrm{MIC}+\mathrm{SE}$ & $\mathrm{MBC}+\mathrm{SE}$ \\
\hline S.mutans & P.granatum + C.sinensis & $3.125+0.01$ & $6.25+0.01$ \\
& C.sinensis+ M.piperita & $3.125+0.01$ & $6.25+0.01$ \\
& M.piperita + P.granatum & $6.25+0.01$ & $6.25+0.01$ \\
\multirow{5}{*}{ S.sanguinis } & P.granatum + C.sinensis & $1.56+0.01$ & $3.125+0.01$ \\
& C.sinensis+ M.piperita & $1.56+0.01$ & $3.125+0.01$ \\
& M.piperita + P.granatum & $3.125+0.01$ & $6.25+0.01$ \\
\hline
\end{tabular}

The combination of P.granatum and C.sinensis similar to C.sinensis and M.piperita revealed the highest effect on S.sanguinis with MIC and MBC values of 1.56 and 3.125 $\mathrm{mg} / \mathrm{ml}$ respectively by using macro-dilution test, as presented in Table 3.

Table-4 shows that the combination of C.sinensis and M.piperita the same as P.granatum and C.sinensis had the highest effect of S.mutans with MIC values of $1.56 \mathrm{mg} / \mathrm{ml}$, but the MBC was different. All the results of Microdilution test for combination extracts on S.mutans and S.sanguinis are presented in Table-4.

Table-3: MIC and MBC of the combination extract by microdilution test (Mean \pm SE are of triplicates)

\begin{tabular}{llll}
\hline Bacteria & Extracts & $\mathrm{MIC}+\mathrm{SE}$ & $\mathrm{MBC}+\mathrm{SE}$ \\
\hline S. mutans & P. granatum + C. sinensis & $1.56+0.01$ & $3.125+0.01$ \\
& C. sinensis + M. piperita & $1.56+0.01$ & $1.56+0.01$ \\
& M.piperita + P. granatum & $3.125+0.01$ & $6.25+0.01$ \\
S. sanguinis & P.granatum + C. sinensis & $1.56+0.01$ & $3.125+0.01$ \\
& C. sinensis + M. piperita & $3.125+0.01$ & $6.25+0.01$ \\
& M.piperita + P. granatum & $3.125+0.01$ & $6.25+0.01$ \\
\hline
\end{tabular}

The best solution containing three extracts of P.granatum, C.sinensis and M.piperita showed the highest antibacterial effect on S.mutans and S.sanguinis in all extracts used in this study by macro- and micro-dilution test. MIC and MBC values for S.mutans were 0.39 and 0.78 $\mathrm{mg} / \mathrm{ml}$ respectively, and for S.sanguinis they were 0.78 and $1.56 \mathrm{mg} / \mathrm{ml}$, respectively. (Figure-1)

Figures-1 \& 2 show the comparison of the MIC of the combinational extract by the macro-dilution test for

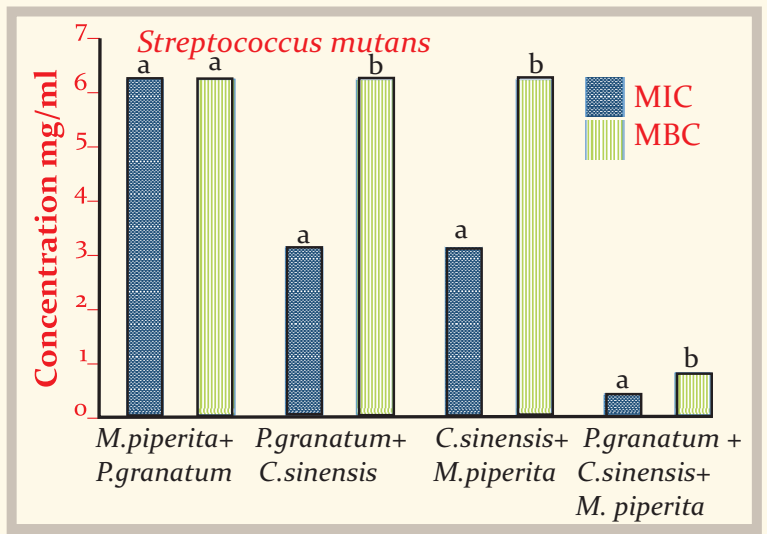

Figure-1: Comparative analysis of mixed extracts on S.mutans by macro-dilution test $(+\mathrm{SE}=0.01$ for all assays) MIC Vs MBS, Bar having similar alphabets do not differ from each Other at $\mathrm{p}<0.05$
Ambient Science, 2019: Vol. 06(1); 31-36 DOI:10.21276/ambi.2019.06.1.ra05

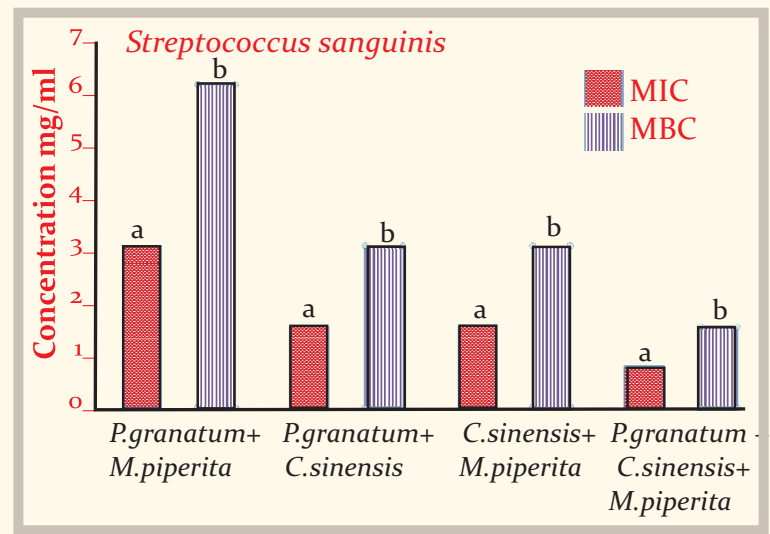

Figure-3: Comparative analysis of mixed extracts on S.sanguinis by macro-dilution test $(+\mathrm{SE}=0.01$ for all assays) MIC Vs MBS, Bar having similar alphabets do not differ from each Other at $\mathrm{p}<0.05$

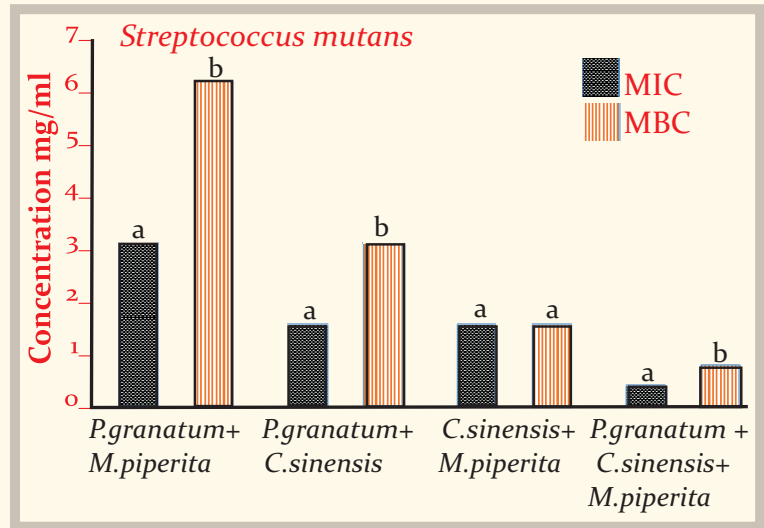

Figure-3: Comparative analysis of mixed extracts on S.mutans by micro-dilution test $(+\mathrm{SE}=0.01$ for all assays) MIC Vs MBS, Bar having similar alphabets do not differ from each Other at $\mathrm{p}<0.05$

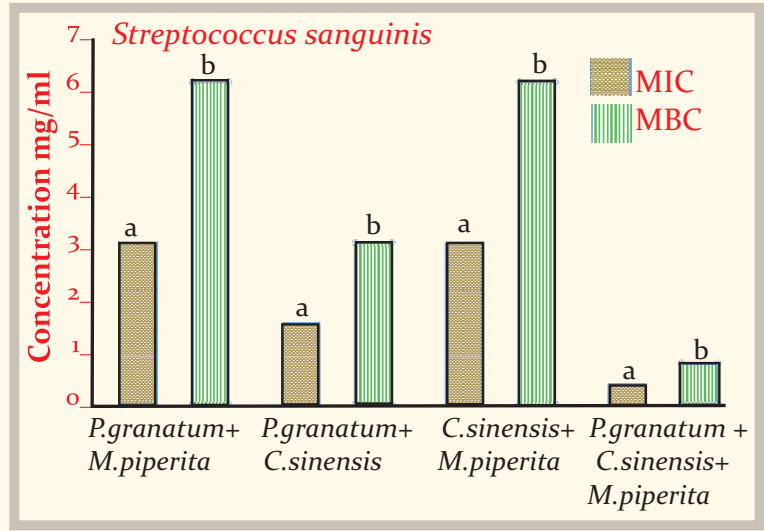

Figure-4: Comparative analysis of mixed extracts on S.sanguinis by micro-dilution test $(+\mathrm{SE}=0.01$ for all assays $)$ MIC Vs MBS, Bar

S.mutans and S.sanguinis. Figures 3 \& 4 show this comparison by micro-dilution test.

\section{Discussion:}

Dental infections are one of the crucial causes of head and neck infections. Risk of serious consequences resulting from the extension of a dental abscess is the most common cause of hospitalization for sepsis caused by oral infections. 
Dental abscesses, if left untreated, can cause brain abscesses and necrotizing inflammation. In most cases, the appropriate diagnosis and treatment of these infections can be prevented. Almost a number of microorganisms including a variety of Streptococcus such as S.mutans, S.sanguinis, S.viridans in addition to Streptococcus anaerobic, cocci anaerobic, Prevotella, Gram-negative bacilli, etc. are involved in the infection of the tooth (Dziedzic et al., 2013).

The reduction of oral microorganisms prior to oral surgery can play a signif icant role in reducing the incidence of postoperative oral infections (Munro \& Grap, 2004; Taheri et al., 2011). Treating with antimicrobial agents with minimal side effects such as filling restoration and teeth pigmentation and unwanted tissue toxicity is very necessary.

Although we found that Punica Granatum, Camelia Sinensis and Mentha Piperita had high antibacterial effects on S.mutans and S.sanguinis, using the three extract combination reveal the synergistic antimicrobial effect and had the highest effect. Lalwani et al. (2014) reported that the extract of P.granatum had an antimicrobial effect against S.mutans, which is in the same line with those of our study. Hajifattahi et al. (2016) reported that P.granatum extract had the greatest influence on the S.mutans and S.sanguinis, their results are very nearer to our study.

In our study, MIC and MBC against green tea extract on S.mutans and S.sanguinis revealed an antimicrobial effect on oral bacteria which resembles the findings of Araghizadeh et al. (2013). Our MIC and MCB results of M.piperita extract on S.mutans, S.sanguinis is also compromised with Shayegh et al. (2008).

The combined effects of herbal extracts has not been well studied before. In the presenting study, MIC and MBC of P.granatum. The extract combination of C.sinensis and M.piperita agaiant S.mutans and S.sanguinis were lower than these values for each extract alone.

These results showed that the combination of these 3 extracts is the most effective antimicrobial extract and signif icantly reduces the MIC and MBC values.

P.granatum has different ingredients such as tannin, flavonoids, polyphenol compounds, ellagitannins, punicalin, alkanoids, punicalagin, organic acid and polyphenolic compositions (Voravuthikunchai et al., 2004; Bassiri-Jahromi et al., 2015; Anibal et al., 2013; Al-Zoreky, 2009).

The effective antimicrobial composition of P.granatum is punicalin, punicalagin tannins (Yadav \& Khan, 2012). These compositions induce protein precipitation in the bacterial cell wall and cause damage (Endo et al., 2010). Phenolic ingredients disrupt bacterial cell membrane, interfere with bacterial DNA, cellular enzymatic activation, bacterial adhesion and induce deprivation induction (Voravuthikunchai et al., 2004; Bassiri-Jahromi et al., 2015; Anibal et al., 2013; Al-Zoreky, 2009; Endo et al., 2010).
As per Golestannejad et al. (2017), M.piperita have a high concentration of menthol and menthone and tannin. The antibacterial effect of it is considerably related to high concentration of menthol, pulegone, isomethone, piperitone, carvone and dehydro carvone(Sivropoulou et al., 1996; Chami et al., 2004).

Hydrophobic properties of herbal extracts make the penetration of these compositions into the cell membrane, more feasible (Mathur et al., 2011).

Regarding the antibacterial properties, Hassan et al. (2018) shown more potency in C.sinensis (green tea) in comparison toa mouthwash showed against S.mutans. It is assumed that polyphenolic compounds of green tea are responsible for inhibition of bacterial attachment to the dental plaque by changing the bacterial phenotype. On the other hand, glycosyl transferase inhibition which can be induced by catechin can decrease plaque formation more potently (Hassan et al., 2018; Tehrani et al., 2011).

Green tea leaves contain fluoride and polyphenols (catechin) which induce dental caries resistance (FournierLarente et al., 2017; Raju et al., 2017; ). As it has been proved previously, fluoride cause bacterial growth inhibition and teeth remineralization (Zafar \& Ahmed, 2015; Zafar, 2013).

In our study, both microbroth and macrobroth dilution methods were used to assess the antibacterial properties of the P.granatum, C.sinensis and M.piperita extracts in their respective lone capacity and as combined. Introducing a new combination of herbal extracts with noticeable antibacterial effects develops a new insight for improving the antimicrobial strength of them. These herbal extracts can be used as mouthwashes and tooth-pastes. Natural products usually have fewer side effects than chemical products. Designing more researches on different extracts of plants and other oral pathologic microbiota can be suggested for future studies.

Acknowledgment:

We would like to thanks the staff of the Department of Microbiology and Central Laboratory Research of Jahrom University of Medical Sciences

\section{References:}

Al-Zoreky, N. (2009): Antimicrobial activity of pomegranate (Punica granatum L.) fruit peels. Int.J. Food Microbiol., 134(3):244-248.

Anibal, P.C., Peixoto, I.T., Foglio, M.A. \& Höfling, J.F. (2013): Antifungal activity of the ethanolic extracts of Punica granatum L. and evaluation of the morphological and structural modifications of its compounds upon the cells of Candida spp. Braz. J. Microbiol., 44(3):839-848.

Bagri, P., Ali, M, Aeri V., Bhowmik, M. \& Sultana, S. (2009): Antidiabetic effect of Punica granatum flowers: effect on hyperlipidemia, pancreatic cells lipid peroxidation and antioxidant enzymes in experimental diabetes. Food Chem. Toxico., 47(1):50-54.

Bassiri-Jahromi, S., Katiraee, F., Hajimahmoodi, M., Mostafavi, E. 


\section{RESEARCH ARTICLE}

Talebi, M., \& Pourshafie, M.R. (2015): In vitro antifungal activity of various Persian cultivars of Punica granatum L. extracts against Candida species. Jundishapur J. Nat. Pharm. Prod., 10(3):e19754.

Chami, N., Chami, F., Bennis, S., Trouillas, J. \& Remmal, A. (2004): Antifungal treatment with carvacrol and eugenol of oral candidiasis in immunosuppressed rats. Braz. J. Infec. Dis., 8(3):217-226.

Chhour, K.L., Nadkarni, M.A., Byun, R., Martin, F.E., Jacques, N.A. \& Hunter, N. (2005): Molecular analysis of microbial diversity in advanced caries. J. Clin. Microbiol., 43(2):843-849.

Chinsembu, K.C. (2016): Plants and other natural products used in the management of oral infections and improvement of oral health. Acta Tropica, (154):6-18.

CLSI (2012): Clinical and Laboratory Standards Institute Standards Development Policies and Process (document Mo7-A9). Pub. by: Clinical and Laboratory Standards Institute, Wayne, PA. P. 59.

Dastjerdi, E.V., Abdolazimi, Z., Ghazanfarian, M., Amdjadi, P., Kamalinejad, M. \& Mahboubi, A. (2014): Effect of Punica granatum L. flower water extract on five common oral bacteria and bacterial biofilm formation on orthodontic wire. Iranian J. Pub. Health, 43(12):1688-1694.

Duman, A.D., Ozgen, M., Dayisoylu, K.S., Erbil, N. \& Durgac, C. (2009): Antimicrobial activity of six pomegranate (Punica granatum L.) varieties and their relation to some of their pomological and phytonutrient characteristics. Molecules. 14(5):18o8-1817.

Dziedzic, A., Kubina, R., Wojtyczka, R.D., Kabala-Dzik, A., Tanasiewicz, M. \& Morawiec, T. (2013): The antibacterial effect of ethanol extract of polish propolis on mutans Streptococci and lactobacilli isolated from saliva. Evi-Based Comp. Alter. Med., 2013:Article ID 681891.

Endo, E.H., Cortez, D.A., Ueda-Nakamura, T., Nakamura, C.V. \& Dias Filho, B.P. (2010): Potent anti-fungal activity of extracts and pure compound isolated from pomegranate peels and synergism with fluconazole against Candida albicans. Res. Microbiol., 161(7):534-540.

Fournier-Larente, J., Morin, M.P. \& Grenier, D. (2016): Green tea catechins potentiate the effect of antibiotics and modulate adherence and gene expression in Porphyromonas gingivalis. Arch. Oral Biol., 65:35-43.

Ghapanchi, J., Bazargani, A., Zariean, A., Rezaee, M., Ranjbar, Z., Karami, A. \& Zamani, A. (2016): Evaluation of the AntiStreptococcus mutans Potential of Petroselinum crispum, an in vitro study. Eur. J. Med. Plants, 15(4):1-8.

Ghapanchi, J., Lavaee, F., Moattari, A. \& Shakib, M. (2015): The antibacterial effect of four mouthwashes against Streptococcus mutans and Escherichia coli. L. Pak. Med. Assoc., 65(4):350-353.

Goenka, P., Sarawgi, A., Karun, V., Nigam, A.G., Dutta, S. \& Marwah, N. (2013): Camellia sinensis (Tea): implications and role in preventing dental decay. Pharmacog. Rev.,7(14):152156.

Golestannejad, Z., Gavanji, S., Mohammadi, E., Motamedi, A., Bahrani, M., Rezaei, F., Larki, B., Mojiri, A. \& Bakhtari, A. (2017): Comparison of antibacterial activity of essential oils of
Ambient Science, 2019: Vol. 06(1); 31-36 DOI:10.21276/ambi.2019.06.1.ra05

Foeniculum vulgare Mill, Mentha arvensis and Mentha piperita against Streptococcus mutans. Adv. Herbal Med., 39(1):3-13.

Gunsolley, J.C. (2010): Clinical efficacy of antimicrobial mouthrinses. J. Dent., 38:S6-S1o.

Hajifattahi, F., Moravej-Salehi, E., Taheri, M., Mahboubi, A. \& Kamalinejad, M. (2016): Antibacterial effect of hydroalcoholic extract of Punica granatum Linn. Petal on common oral microorganisms. Int. J. Biomat., Article ID 8098943 .

Hassan, S.A., Metwalli, N.E., Ibrahim, G.G. \& Aly, M.A. (2018): Comparison of the eff icacy of mouth rinses Camellia sinensis extract, guava leaves extract and sodium fluoride solution, on Streptococcus mutans and Lactobacillus in children (an in vivo study). (in press) doi.org/10.1016/j.fdj.2018.11.002

Hillman, J.D., Socransky, S.S. \& Shivers, M. (1985): The relationships between Streptococcal species and periodontopathic bacteria in human dental plaque. Arch. Oral Biol., 30(11-12):791-795.

Holbrook, W.P. \& Magnúsdóttir, M.O. (2012): Studies on strains of Streptococcus mutans isolated from caries-active and cariesfree individuals in Iceland.J. Oral Microbiol., 4(1):10611.

Jorgensen, J.H. \& Turnidge, J.D. (2015): Susceptibility test methods: dilution and disk diffusion methods, p. 1253-1273. In: Jorgensen, J.H., Pfaller, M.A., Carroll, K.C., Funke, G. Landry, M.L., Richter, S.S. \& Warnock, D.W (eds.) Manual of Clinical Microbiology, Eleventh Edition. Pub. by: American Society of Microbiology.

Jurenka, J.S. (2008): Therapeutic applications of pomegranate (Punica granatum L.): a review. Altern. Med. Rev., 13(2):128144

Lalwani, V., Koneru, A., Vanishree, M., Vardendra, M., Hunasgi, S. \& Surekha, R. (2014): Anti-microbial activity of Punica granatum on Streptococcus in dental caries patients and healthy individuals: a comparative study. J. Adv. Clin. Res., Ins.,1(3):94-98.

Lavaee, F., Faez, K., Faez, K., Hadi, N. \& Modaresi, F. (2016): Antimicrobial and antibiofilm activity of silver, titanium dioxide and iron nano particles. Am. J. Dent., 29(6):315-320.

Lavaee, F., Ghapanchi, J., Motamedifar, M. \& Sorourian, S. (2018): An in vitro analysis of the effects of iron sulfate and iron acetate on Streptococcus mutans. J. Dent. Biomat., 5(1):527531.

Mathur, A., Prasad, G.B.K.S., Rao, N., Babu, P. \& Dua, V.K. (2011): Isolation and identification of anti-micribial compound from Mentha pipirita. Rasayan J., 4(1):36-42.

Menezes, S.M., Cordeiro, L.N. \& Viana, G.S. (2006): Punica granatum (pomegranate) extract is active against dental plaque. J. Herbal Pharma., 6(2):79-92.

Mitscher, L.A., Jung, M., Shankel, D., Dou, J.H., Steele, L. \& Pillai, S.P. (1997): Chemoprotection: a review of the potential therapeutic antioxidant properties of green tea (Camellia sinensis) and certain of its constituents. Med. Res. Rev., $17(4): 327-365$.

Munro, C.L. \& Grap, M.J. (2004): Oral health and care in the intensive care unit: state of the science. Am. J. Crit. Care, 13(1):25-33. 
Palmer, E.A., Vo, A., Hiles, S.B., Peirano. P., Chaudhry, S., Trevor, A., Kasimi, I., Pollard, J., Kyles, C., Leo, M., Wilmot, B., Engle, J., Peterson, J., Maier, T. \& Machida, C.A. (2012): Mutans streptococci genetic strains in children with severe early childhood caries: follow-up study at one-year post-dental rehabilitation therapy. J. Oral Microbiol., 4(1):19530.

Palombo, E.A. (2011): Traditional medicinal plant extracts and natural products with activity against oral bacteria: potential application in the prevention and treatment of oral diseases. Evi-based Compl.Altern. Med., Article ID 680354

Raju, R., Divya, A., Rajendran, G. \& John, J.R. (2017): Analogous assay between green tea mouthwash, listerine mouthwash and chlorhexidine mouthwash in plaque reduction, on orthodontic patients: a randomized cross-over study. Int. J. Comm. Med. Pub. Health, 4(5):1429-1435.

Rezazadeh, F., Bazargani, A., Roozbeh-Shahroodi, J., Pooladi, A., Arasteh, P. \& Zamani, K. (2016): Comparison of oral Lactobacillus and Streptococcus mutans between diabetic dialysis patients with non-diabetic dialysis patients and healthy people. J. Renal Injury Prevent., 5(3):148-152

Rodrigues, C.R., Faquin, V., Trevisan, D., Pinto, J.E.P.B., Bertolucci, S.K.V. \& Rodrigues, T.M. (2004): Nutrição mineral, crescimento e teor de óleo essencial da menta em solução nutritiva sob diferentes concentrações de fósforo e épocas de coleta. Horticul. Brasileira, 22(3):573-578.

Semyari, H., Owlia, P, Farhadi, S. \& Tabrizi, S.M. (2011): Evaluation of antimicrobial effect of Ammi visnaga against oral Streptococci. J. Microbiol. Antimicrobials, 3(5):126-129.

Shayegh, S., Rasooli, I., Taghizadeh, M., Astaneh S.D.A. (2008): Phytotherapeutic inhibition of supragingival dental plaque. Nat. Product Res., 22(5):428-439.

Sivropoulou, A., Papanikolaou, E., Nikolaou, C., Kokkini, S., Lanaras, T. \& Arsenakis, M. (1996): Antimicrobial and cytotoxic activities of Origanum essential oils. J. Agricul. Food Chem., 44(5):1202-1205.

Taheri, J.B., Azimi, S., Raf ieian, N. \& Zanjani H.A. (2011): Herbs in dentistry. Int. Dental.J., 61(6):287-296.
Tahir, A. \& Moeen, R. (2011): Comparison of antibacterial activity of water and ethanol extracts of Camellia sinensis (L.) Kuntze against dental caries and detection of antibacterial components. J. Med. Plants Res., 5(18):4504-4510.

Taweechaisupapong, S., Choopan, T., Singhara, S., Chatrchaiwiwatana, S. \& Wongkham, S. (2005): In vitro inhibitory effect of Streblus asper leaf-extract on adhesion of Candida albicans to human buccal epithelial cells. I. Ethnopharmacol., 96(1-2):221-226.

Tehrani, M.H., Asghari, G. \& Hajiahmadi, M. (2011): Comparing Streptococcus mutans and Lactobacillus colony count changes following green tea mouth rinse or sodium fluoride mouth rinse use in children (Randomized double-blind controlled clinical trial). Dental Res. J., 8(Suppl-1):S58-63.

Vahabi, S., Najafi, E. \& Alizadeh, S. (2011): In vitro antimicrobial effects of some herbal essences against oral pathogens. L. Med. Plants Res., 5(19):4870-4878.

Vasconcelos, L.C., Sampaio, F.C., Sampaio, M.C., Pereira, Mdo. S., Higino, J.S. \& Peixoto, M.H. (2006): Minimum inhibitory concentration of adherence of Punica granatum Linn (pomegranate) gel against $S$. mutans, S. mitis and C. albicans. Braz. Dental J., 17(3):223-227.

Voravuthikunchai S., Lortheeranuwat, A., Jeeju, W., Sririrak, T., Phongpaichit, S. \& Supawita, T. (2004): Effective medicinal plants against enterohaemorrhagic Escherichia coli O157: H7. J. Ethnopharmacol. , 94(1):49-54.

Yadav, M. \& Khan, K.K. (2012): Antimicrobial activity of some ethnomedicinal plants used by Tribes of Rewa, Madhya Pradesh. Indian J. Life Sci., 1(2):35-38.

Zafar, M.S. \& Ahmed, N. (2015): Therapeutic roles of fluoride released from restorative dental materials. Fluoride., 48(3): 184-194.

Zafar, M.S. (2013): Effects of surface pre-reacted glass particles on fluoride release of dental restorative materials. World Appl. Sci.J., 28(4):457-462. 